\title{
Evaluation of the influence of subinguinal varicocelectomy procedure on seminal parameters, reproductive hormones and testosterone/estradiol ratio
}

\author{
Ünal Öztekin, Mehmet Caniklioglu, Sercan Sarı, Volkan Selmi, Abdullah Gürel, Mehmet Şakir \\ Taşpınar, Levent Işıkay \\ Bozok University Faculty of Medicine, Department of Urology, Yozgat, Turkey.
}

\begin{abstract}
Summary Objective: Varicocele is the most commonly surgically curable cause of male infertility.

However, the mechanisms related to the effect of reducing fertility potential have not been clearly identified. The aim of this study was to investigate the effects of varicocelectomy on semen parameters, reproductive hormones and testosterone / estradiol ratio.

Matherial and methods: Fifty seven patients outcomes were evaluated before and 6 months after subinguinal microsurgical varicocelectomy. Semen parameters, reproductice hormones and testosteron/estradiol ratio results of patients were compared retrospectively.

Results: The mean age was 26.8 years. Fifty four (94.7\%) patients had grade 3 and $3(5.3 \%)$ patients had grade 2 varicocele. There was a significant increase in semen parameters except semen volume. There was a statistically significant increase in serum testosterone levels, but not on testosteronel estradiol ratio.

Conclusions: According to our results, microsurgical subinguinal varicocelectomy can be recommended for both improving semen parameters and hormonal recovery.
\end{abstract}

KEY WORDS: Varicocele; Testosterone; Testosterone/Estradiol ratio; Semen parameters; Reproductive hormones.

Submitted 14 September 2019; Accepted 23 December 2019

\section{INTRODUCTION}

Varicocele is a genital abnormality that disrupts the growth and development of the ipsilateral testis and can also reduce the quality of life due to pain symptoms. It is seen in $11.7 \%$ of adult males and $25.4 \%$ of whose with abnormal sperm parameters. It is thought to cause hypogonadism and to be associated with male subfertility (1). Varicocele is the most commonly surgically curable cause of male infertility (2). Pain and feeling of scrotal fullness are also indications for surgical treatment (3). Factors such as reflux of kidney and adrenal metabolites, hypoxia, endocrine disorders, increased sperm DNA fragmentation, oxidative stress, increased intratesticular apoptosis, and disruption of intratesticular enzymes due to temperature increase have been implicated in the etiology (4). However, the mechanisms related to the effect of reducing fertility potential have not been clear- ly identified (1). There is also limited evidence of how Leyding cells and testosterone production are affected after varicocelectomy and how much it changes testosterone production (5).

In the literature, it is generally indicated that Leydig cell function is negatively affected in varicocele patients with decreased testosterone production and that also hormone level is improved by varicocelectomy $(4,6,7)$. Studies on rats have shown pathological changes such as increased apoptosis of Leydig and Sertoli cells causing decreased viability and testosterone synthesis due to varicocele $(8,9)$. However, there are studies advocating that varicocelectomy has no effect on serum testosterone levels in human studies $(3,10,11)$.

Local hormonal balance between testicular testosterone and estradiol ratio is effective on spermatogenesis. Impairment of this balance in semen and serum can cause infertility by disrupting normal spermatogenesis.

Varicocelectomy can positively affect the balance between testosterone and testosterone/estradiol ratio (T/E) (4). Therefore, evaluating T/E ratio changes may provide more useful information (12).

The aim of this study was to investigate the effects of varicocelectomy on sperm parameters, reproductive hormones and T/E ratio.

\section{Materials AND METHOdS}

Data of patients who presented with infertility and/or pain and then underwent microsurgical subinguinal varicocelectomy between November 2017 and July 2019 were evaluated retrospectively. After approval from the local ethics committee, patients aged 18 and over were included in the study and the study was conducted in accordance with the Declaration of Helsinki. Fifty seven patients who met the study criteria were evaluated. All patients were examined while standing and evaluated with Valsalva maneuver and then color flow doppler ultrasonography (CFDU) was performed. Patients were classified according to clinical grading system.

Grade 0 (subclinical): cannot be detected by inspection or palpation but can only be detected by CFDU. Grade I: only palpable on Valsalva maneuver. 
Grade II: palpable without Valsalva maneuver. Grade III: visible with no need for palpation. Patients with known or detected hormonal pathology (hypo/hypergonadism, hypo/hyperthyroidism, hyperprolactinemia), azoospermia and cryptozoospermia $(\leq 1$ million $/ \mathrm{mL})$, body mass index $(B M I) \geq 30 \mathrm{~kg} / \mathrm{m}^{2}$, genital tract infection (orchitis, epididymitis, urethritis) and patients who had used chemotherapeutic drugs were excluded from the study. Semen analyses were performed after 3-7 days of abstinence using the 2010 criteria of the World Health Organization (13). Semen volume, sperm concentration, total sperm count, progressive motility and total motility data were recorded as semen parameters before and 6 months after varicocelectomy. Age, body mass index, hormone profiles including follicle stimulating hormone (FSH), luteinizing hormone (LH), prolactin (PRL), estradiol (E2) and total testosterone (T) results and T/E ratios were recorded.

Subinguinal incision was performed and microsurgical varicocelectomy procedure was performed by defining spermatic cord from external inguinal ring in all patients. Preoperative and postoperative results of patients were compared retrospectively.

\section{Statistical analysis}

All statistical tests were performed using the Statistics Package for Social Sciences version 25 (IBM SPSS $^{\circledR}$, Chicago, IL). KolmogorovSmirnov test was used to determine the normal distribution of data. Paired-sample T-test was used for pre-postoperative comparison of parametric data and Wilcoxon Signed Ranks Test was used for pre-postoperative comparison of non-parametric data. A value $\mathrm{p}<0.05$ was considered statistically significant.
Table 1.

Overall and specific course rating.

\begin{tabular}{|lc|}
\hline Age (mean) (min-max) & $26.8(18-41)$ \\
\hline BMl kg/m² (mean)(min-max) & $24.77(18.31-29.41)$ \\
\hline Testosterone change & \\
\hline No increase (n) & $21(36.8 \%)$ \\
\hline $0-50 \%$ increase (n) & $31(54.3 \%)$ \\
\hline $50-100 \%$ increase $(\mathrm{n})$ & $5(8.7 \%)$ \\
\hline BMI: Body Mass Index. & \\
\hline
\end{tabular}

Table 2.

Comparison of semen parameters before and after varicocelectomy.

\begin{tabular}{|lccc|}
\hline & Preoperative & Postoperative & P value \\
\hline Semen volume, $\mathrm{ml}($ mean \pm SD) & $3.12 \pm 1.39$ & $3.33 \pm 1.56$ & $0.105^{\mathrm{b}}$ \\
\hline Sperm concentration (mil/ml) (mean \pm SD) & $35.54 \pm 24.76$ & $45.13 \pm 23.76$ & $0.001^{\mathrm{a}}$ \\
\hline Total sperm count, (mil) (mean \pm SD) & $113.44 \pm 98.54$ & $153.84 \pm 115.98$ & $<0.001^{\mathrm{b}}$ \\
\hline Progressive motility (Type A) (\%) & $24.71 \pm 10.57$ & $28.95 \pm 9.95$ & $0.001^{\mathrm{a}}$ \\
\hline Total motility (Type A+B) (\%) & $41.96 \pm 16.00$ & $45.14 \pm 14.63$ & $0.011^{\mathrm{b}}$ \\
\hline a Calculated using Paired-sample T-test. ${ }^{\mathrm{b}}$ Calculated using Wilcoxon Signed Ranks Tests. SD: standard deviation. & \\
\hline
\end{tabular}

Table 3.

Comparison of hormonal data before and after varicocelectomy.

\begin{tabular}{|c|c|c|c|}
\hline & Preoperative & Postoperative & P value ${ }^{b}$ \\
\hline Serum FSH, mlU/ml (mean \pm SD) & $3.69 \pm 2.69$ & $3.73 \pm 2.50$ & 0.689 \\
\hline$\overline{\text { Serum LH, mlU/ml (mean } \pm \text { SD) }}$ & $3.33 \pm 1.51$ & $3.32 \pm 1.68$ & 0.161 \\
\hline$\overline{\text { Serum PRL, ng/ml (mean } \pm \text { SD) }}$ & $10.20 \pm 3.96$ & $9.86 \pm 3.35$ & 0.609 \\
\hline Serum E2, ng/L (mean \pm SD) & $24.88 \pm 8.78$ & $26.48 \pm 9.02$ & 0.445 \\
\hline$\overline{\text { Serum T, ng/dl (mean } \pm S D)}$ & $507.63 \pm 174.27$ & $547.01 \pm 184.59$ & 0.003 \\
\hline$\overline{\mathrm{T} / \mathrm{E} 2 \text { (mean } \pm \mathrm{SD} \text { ) }}$ & $22.36 \pm 9.46$ & $22.87 \pm 11.10$ & 0.978 \\
\hline
\end{tabular}

\section{Results}

A total of 57 patients aged 18-41 (mean: 26.8) were included in the study. The mean BMI value was 24.77 (18.31-29.41) $\mathrm{kg} / \mathrm{m}^{2}$. The varicocele grade was grade 2 in $3(5.3 \%)$ patients who underwent varicocelectomy. Fifty four (94.7\%) patients had grade 3 varicocele.

In 21 (36.8\%) of the patients, no increase was observed according to the preoperative testosterone values, while $31(54.3 \%)$ had less than $50 \%$ and $5(8.7 \%)$ had more than $50 \%$ change (Table 1 ).

There was no significant difference between preoperative and postoperative semen volumes. There was a statistically significant improvement in sperm concentration, total sperm count, progressive and total sperm motility compared to preoperative period $(\mathrm{p}<0.05$ ) (Table 2 ).

There were no significant changes in serum FSH, LH, E2, PRL values compared to preoperative values. There was a statistically significant increase in serum testosterone levels $507.63 \pm 174.27,547.01 \pm 184.59 \mathrm{ng} / \mathrm{dl}$ preoperatively and postoperatively, respectively $(\mathrm{p}=0.003)$. However, T/E ratios (preoperative and postoperative $22.36 \pm 9.46,22.87 \pm 11.10$, respectively) were not significantly changed $(\mathrm{p}=0.978)$ (Table 3$)$.

\section{Discussion}

Varicocele is an abnormal dilation of the plexus pampiniformis and testicular spermatic veins in the spermatic cord (14). It is often caused by left side veins and is a venous dilatation disorder characterized by increased pressure within the internal spermatic vein (6). It affects male fertility by creating anatomical and functional damage within the testis (15). It has been reported that patients with varicocele have higher degree of sperm DNA fragmentation when compared to healthy individuals. Also, varicocele patients with abnormal sperm parameters have higher fragmentation levels than those with normal sperm parameters (16). More severe damage to the testicle has been reported as the degree of varicocele increases (17). Increased venous pressure in the varicocele, which is a dilated venous disease, can cause venous stasis by delaying vascular washout, resulting in impaired thermal regulation leading to hyperthermia and accumulation of toxins (18). As a result of hyperthermia, it has been suggested that after germ cell apoptosis, inhibition of enzymes involved in spermatogenesis (19) and steroid biosynthesis decreases conver- 
sion to intratesticular testosterone and synthesis (20). In support of this theory, studies advocating increased testosterone levels after varicocelectomy are presented. In the study of Tanrikut et al. (6), they reported the results of testosterone before and after varicocelectomy as $416 \mathrm{ng} / \mathrm{dL}$ and $469 \mathrm{ng} / \mathrm{dL}$ respectively in their series of 325 patients with palpable varicocele. They showed a significant increase in testosterone level in two thirds of patients after varicocelectomy. The results of our study were $507.63 \pm 174.27$ and $547.01 \pm 184.59 \mathrm{ng} / \mathrm{dl}$ before and after surgery respectively and there was a significant increase ( $p=0.003)$. Similarly, two-thirds of our patients had increased testosterone. In the study by Sathya S. et al, testosterone levels increased from $1.77 \pm 0.18 \mathrm{ng} / \mathrm{ml}$ to $3.01 \pm 0.43 \mathrm{ng} / \mathrm{ml}$ after varicocelectomy (21). Hsiao et al. likewise stressed that there was a significant increase in testosterone level and sperm concentration and total sperm count in all varicocelectomy patients, including the $5^{\text {th }}$ and $6^{\text {th }}$ decade age group (22). In a meta-analysis evaluating 814 patients, it was concluded that surgical treatment of varicocele significantly increased Leyding cell function and testosterone production (23).

Numerous studies have shown that testosterone levels are elevated after varicocelectomy, but there are also studies advocating that it does not cause any changes. In the study by Rodriguez et al., there was no relationship between varicocele and low testosterone. It was also argued that there was no improvement in semen profile in treated varicoceles (10). Similarly, Panach-Navarrete et al. showed that there was no correlation between the presence of varicocele and decreased serum testosterone level (11). Zheng et al. detected that there is not significant change in testosterone levels compared to preoperative values in 104 infertile patients after left or bilateral varicocelectomy procedure (24).

Although the prevalence of varicocele is widespread worldwide and associated with low testosterone levels, this relationship has not been clearly demonstrated.

In this context, it is considered that $\mathrm{T} / \mathrm{E}$ ratio evaluation can provide more useful information (12). Simorangkir et al. concluded that the T/E2 ratio in pampiniform plexus was significantly lower than in the control group in their study by creating varicocele in a rabbit model (25). Although there are limited studies on this subject in the literature, the pre and postoperative T/E ratio was found to be $19 \pm 7.7$ and $27.5 \pm 1.2$ in the prospective study conducted by Gomaa et al. (4). They emphasized that there was a significant postoperative decrease in E2 level $(26.9 \pm 3.2$ and $22.9 \pm 3.1 \mathrm{pg} / \mathrm{ml} \mathrm{p}<0.001$, respectively). In our study, T/E2 ratios were $22.36 \pm 9.46$ and $22.87 \pm 11.10$, before and after surgery, respectively $(\mathrm{p}=$ 0.978 ). There was an increase in postoperative serum E2 values but it was not statistically significant $(p=0.445)$. When we evaluated only 36 patients with increased testosterone levels, the mean preoperative and postoperative E2 levels were $23.85 \pm 9.17$ and $26.92 \pm 9.57 \mathrm{ng} / \mathrm{L}$ $(p=0.104)$, respectively. There was an increase in E2 values with increasing $T$ levels. However, it was not statistically significant. In addition, there was no significant increase in T/E ratios in this patient group ( $\mathrm{p}=0.470)$. No significant difference was found between the two groups whose $\mathrm{T}$ level increased and showed no change $(p=0.212)$. Therefore, it is suggested that these changes may be in the testicular cells regardless of peripheral aromatase activity. Although these results suggest that improvement in Leydig cell functions after varicocelectomy may increase estradiol production, further prospective randomized studies with more patients and longterm follow-up are needed.

A meta-analysis of 548 patients evaluating seven studies emphasized that varicocelectomy provided significant improvement, particularly on progressive sperm motility (26). In another meta-analysis, the varicocelectomy group was compared to the untreated group in terms of semen parameters in adolescents, but no difference was observed between the two groups (27). In general, it is seen that microsurgical varicocelectomy increases sperm concentration and motility (28). Also, there was a significant increase in semen volume, sperm concentration and total number, progressive and total motility after varicocelectomy in our study.

Retrospective design of our study is a limitation. Other limitations include low number of study population and short follow-up, collection of single-centered data, and failure to evaluate pregnancy outcomes.

\section{Conclusions}

When the data of our study were evaluated, we concluded that subinguinal varicocelectomy procedure with microsurgical method provided significant improvement on semen parameters and testosterone levels. However, we did not find a significant relationship between T/E2 ratio and surgery. According to our results, microsurgical subinguinal varicocelectomy can be recommended for both improving semen parameters and hormonal recovery. However, multicenter prospective randomized studies are needed to clarify relationship with reproductive hormones and semen parameters, including more patients with long-term follow-up and pregnancy rate evaluation.

\section{References}

1. Jungwirth A, Diemer T, Kopa Z, et al. EAU Guidelines on Male Infertility. In: Jungwirth A, editor. EAU Guidelines 2018. Arnhem: EAU Guidelines Office. 2018; pp. 734-5.

2. Sabanegh E, Agarwal A. Male Infertility. Tenth Edition. ed. Kavoussi L, Partin A, Novick A, Peters C, editors: Campbell Walsh Urology. 2012; pp 617-42.

3. Resorlu B, Kara C, Sahin E, Unsal A. The significance of age on success of surgery for patients with varicocele. Int Urol Nephrol. 2010; 42:351-6.

4. Gomaa MD, Motawaa MA, Al-Nashar AM, El-Sakka AI. Impact of subinguinal varicocelectomy on serum testosterone to estradiol ratio in male patients with infertility. Urology. 2018; 117:70-7.

5. Tanrikut C, Goldstein M. Varicocele repair for treatment of androgen deficiency. Curr Opin Urol. 2010; 20:500-2.

6. Tanrikut C, Goldstein M, Rosoff JS, et al. Varicocele as a risk factor for androgen deficiency and effect of repair. BJU Int. 2011; 108:1480-4.

7. Ando S, Giacchetto C, Colpi G, et al. Physiopathologic aspects of Leydig cell function in varicocele patients. J Androl. 1984; 5:163-70. 
8. Oh YS, Jo NH, Park JK, Gye MC. Changes in inflammatory cytokines accompany deregulation of claudin-11, resulting in interSertoli tight junctions in varicocele rat testes. J Urol. 2016; 196:1303-12.

9. Luo DY, Yang G, Liu JJ, et al. Effects of varicocele on testosterone, apoptosis and expression of StAR mRNA in rat Leydig cells. Asian J Androl. 2011; 13:287-91.

10. Rodriguez Pena M, Alescio L, Russell A, et al. Predictors of improved seminal parameters and fertility after varicocele repair in young adults. Andrologia. 2009; 41:277-81.

11. Panach-Navarrete J, Morales-Giraldo A, Ferrandis-Cortes C, et al. Is there a relationship between varicocele and testosterone levels? Aging Male. 2019:1-7.

12. Parekattil SJ, Agarwal A. Male Infertility: Contemporary Clinical Approaches, Andrology, ART \& Antioxidants. Male Infertility: Springer Science \& Business Media. 2012; pp. 247-59.

13. World Healt Organization: Laboratory manual for the examination and processing of human semen, 5th ed. Geneva: WHO press; 2010.

14. Lomboy JR, Coward RM. The Varicocele: Clinical Presentation, Evaluation, and Surgical Management. Semin Intervent Radiol. 2016; 33:163-9.

15. Yildiz O, Gul H, Ozgok Y, et al. Increased vasoconstrictor reactivity and decreased endothelial function in high grade varicocele; functional and morphological study. Urol Res. 2003; 31:323-8.

16. Alargkof V, Kersten L, Stanislavov R, et al. Relationships between sperm DNA integrity and bulk semen parameters in Bulgarian patients with varicocele. Arch Ital Urol Androl. 2019; 91:2.

17. Steckel J, Dicker AP, Goldstein M. Relationship between varicocele size and response to varicocelectomy. J Urol. 1993; 149:769-71.

18. Eisenberg ML, Lipshultz LI. Varicocele-induced infertility: Newer insights into its pathophysiology. Indian J Urol. 2011; 27:58-64.
19. Wang C, Cui YG, Wang XH, et al. transient scrotal hyperthermia and levonorgestrel enhance testosterone-induced spermatogenesis suppression in men through increased germ cell apoptosis. J Clin Endocrinol Metab. 2007; 92:3292-304.

20. Rajfer J, Turner TT, Rivera F, et al. Inhibition of testicular testosterone biosynthesis following experimental varicocele in rats. Biol Reprod. 1987; 36:933-7.

21. Sathya Srini V, Belur Veerachari S. Does varicocelectomy improve gonadal function in men with hypogonadism and infertility? Analysis of a prospective study. Int J Endocrinol. 2011; 2011:916380.

22. Hsiao W, Rosoff JS, Pale JR, et al. Older age is associated with similar improvements in semen parameters and testosterone after subinguinal microsurgical varicocelectomy. J Urol. 2011; 185:620-5.

23. Li F, Yue H, Yamaguchi K, et al. Effect of surgical repair on testosterone production in infertile men with varicocele: a metaanalysis. Int J Urol. 2012; 19:149-54.

24. Zheng YQ, Gao X, Li ZJ, et al. Efficacy of bilateral and left varicocelectomy in infertile men with left clinical and right subclinical varicoceles: a comparative study. Urology. 2009; 73:1236-40.

25. Simorangkir L, Sihombing AT, Noegroho BS. Estrogen-testosterone ratio in plexus pampiniform of normal rabbits and rabbits with left artificial varicocele. Indonesian Journal of Urology. 2013; 20:1-4.

26. Kim HJ, Seo JT, Kim KJ, et al. Clinical significance of subclinical varicocelectomy in male infertility: systematic review and metaanalysis. Andrologia. 2016; 48:654-61.

27. Zhou T, Zhang W, Chen Q, et al. Effect of varicocelectomy on testis volume and semen parameters in adolescents: a meta-analysis. Asian J Androl. 2015; 17:1012-6.

28. Yuan R, Zhuo H, Cao D, Wei Q. Efficacy and safety of varicocelectomies: A meta-analysis. Syst Biol Reprod Med. 2017; 63:120-9.

\author{
Correspondence \\ Unnal Öztekin, MD (Corresponding Author) \\ dr_unal@hotmail.com \\ Mehmet Caniklioğlu, MD \\ dr.mehmetcaniklioglu@gmail.com \\ Sercan Sarl, MD \\ sercansari92@hotmail.com \\ Volkan Selmi, MD \\ volkanselmi@hotmail.com \\ Abdullah Gürel, MD \\ abdullahgurel@hotmail.com \\ Mehmet Sakir Taspinar \\ mehmetsakirtaspinar@hotmail.com \\ Levent Işıkay, MD \\ isikay@gmail.com \\ Yozgat Bozok University, Research and Application Hospital, \\ Urology Department, Yozgat, Turkey
}

